\title{
How the Asian subtropical area became evergreen since the Last Glacial Maximum
}

\author{
Zhuo Zheng', K. Huang', Q. Wan' and R. Cheddadi²
}

\begin{abstract}
The onset of the evergreen forest expansion throughout subtropical eastern Asia took place progressively from the tropical latitudes after the Younger Dryas and ended between 8000 and 6000 years BP.
\end{abstract}

Eastern subtropical Asia (ESA) is a territory about the size of Europe and corresponds to a vast ecotonal area between the tropical and the northern temperate climate systems. ESA underwent a tremendous biome turnover over the last glacial/ interglacial transition ( $\mathrm{Ni}$ et al. 2010). Today, the evergreen broad-leaved (EBL) biome prevails in ESA, and during the last glacial period it was dominated by a fragmented deciduous broad-leaved (DBL) vegetation (Yue et al. 2012) over the mountain landscapes and open vegetation at lower altitudes (Yu et al. 2017). The EBL biome (known as laurophyllous forest), currently the most widely distributed biome in eastern Asia, extends from about $22^{\circ} \mathrm{N}$ to $33^{\circ} \mathrm{N}$ under a monsoon regime.

The replacement of the scattered DBL biome by a denser and more continuous EBL forest took place during the transition from the last glacial period to the warmer and wetter Holocene. However, there are major questions concerning the timing, dynamics, and causes of such a large biome transformation over the subtropical belt in China (Zhao et al. 2009). Different and concomitant climate variables, such as an increase of temperature (during both summer and winter) and/or the seasonal changes in precipitation related to an increased monsoon (Zhou et al. 2016) after the glacial termination, might have favored the spread of the EBL at the expense of the deciduous biome. Fossil records collected in ESA can provide us with useful information about such a large-scale biome change.

\section{Timing and dynamics}

Although the forest was not the only dominant ecosystem during the last glacial period, the DBL forest covered a large part of southern China that is dominated today by the EBL biome (Fig. 1a and 1b). A high-resolution pollen record collected in the center of the subtropical zone shows that until the last Heinrich event $(\mathrm{H} 1$, dated to around 16.5 thousand years before present, kyr BP) the main forest populations in southern China were composed of deciduous rather than evergreen species (Fig. 1c). However, the complete absence of the EBL biome north of $24^{\circ} \mathrm{N}$ during the Last Glacial Maximum (LGM; Ni et al. 2010) seems to not be coherent with the phylogeographic studies that suggest some species composing the EBL biome survived during the LGM in situ in numerous northern refugia (Fan et al. 2016).

The postglacial expansion of the EBL biome over the subtropical zone primarily began at the Bølling/Allerød (B/A) warming (around $14 \mathrm{kyr}$ BP), but more substantial replacement occurred after the Younger Dryas (YD) cooling (12.7-11.5 kyr BP). A major massive migration took place from the southern tropical belt of eastern Asia rather than from the putative scattered northern refugia, suggested by the phylogeographic studies. In the western high Tibetan plateau, within the subtropical zone, despite a different vegetation type during the LGM (sclerophyllous mixed oak and conifer forests), there is also simultaneously a profound biome change over the altitudinal belts (Wang et al. 2018; Nishimura et al. 2014; Cheng et al. 2018). The transitional turnover from DBL
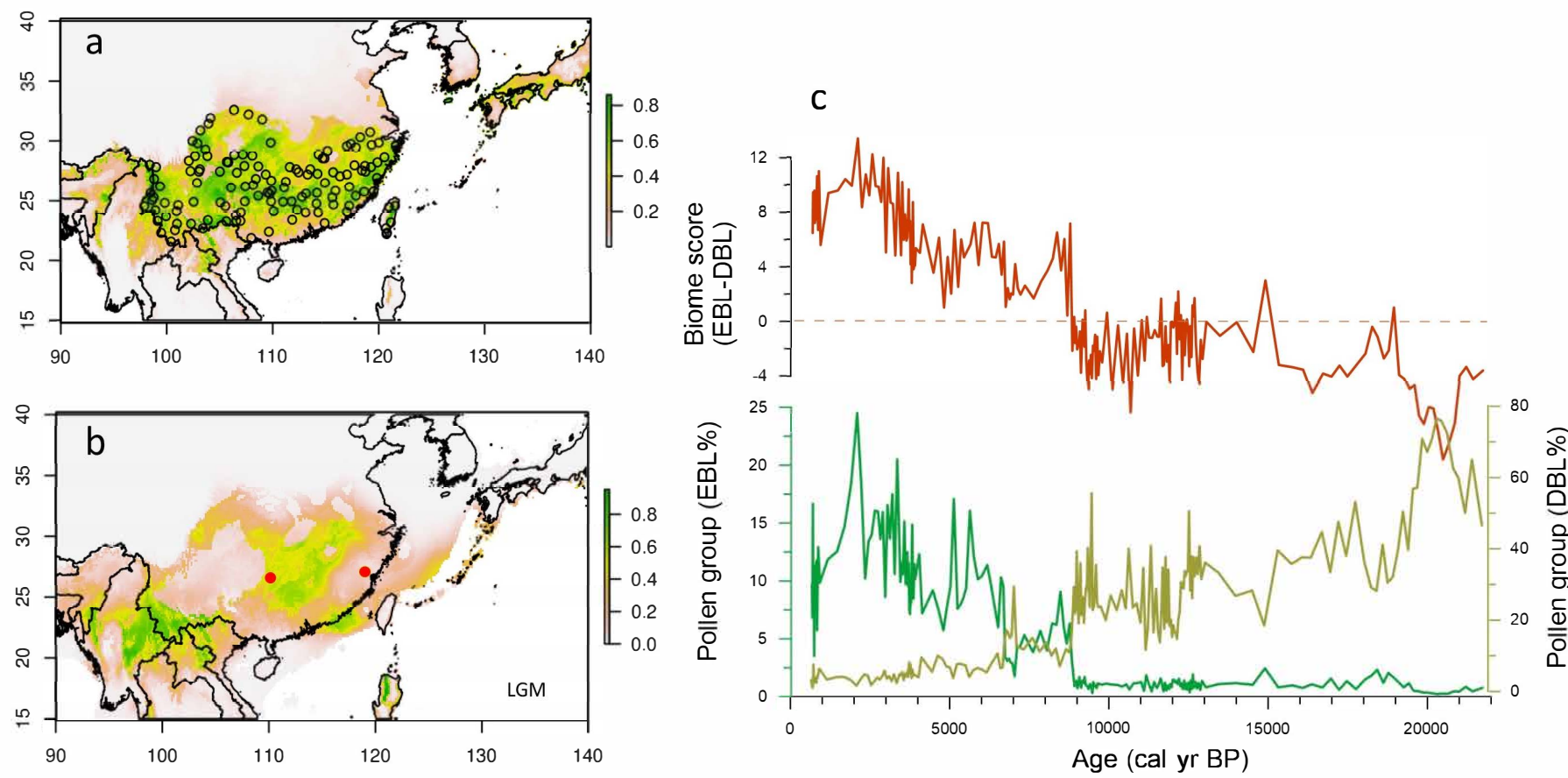

Figure 1: Potential distribution of evergreen broad-leaved forest simulated by species distribution model for the (A) present-day and (B) LGM compared with (C) pollen groups and biome scores from a coring (SZY) collected in southeast China. The random selected points (circles) in (A) are extracted from digitized present-day evergreen broad-leaved forest distribution. 


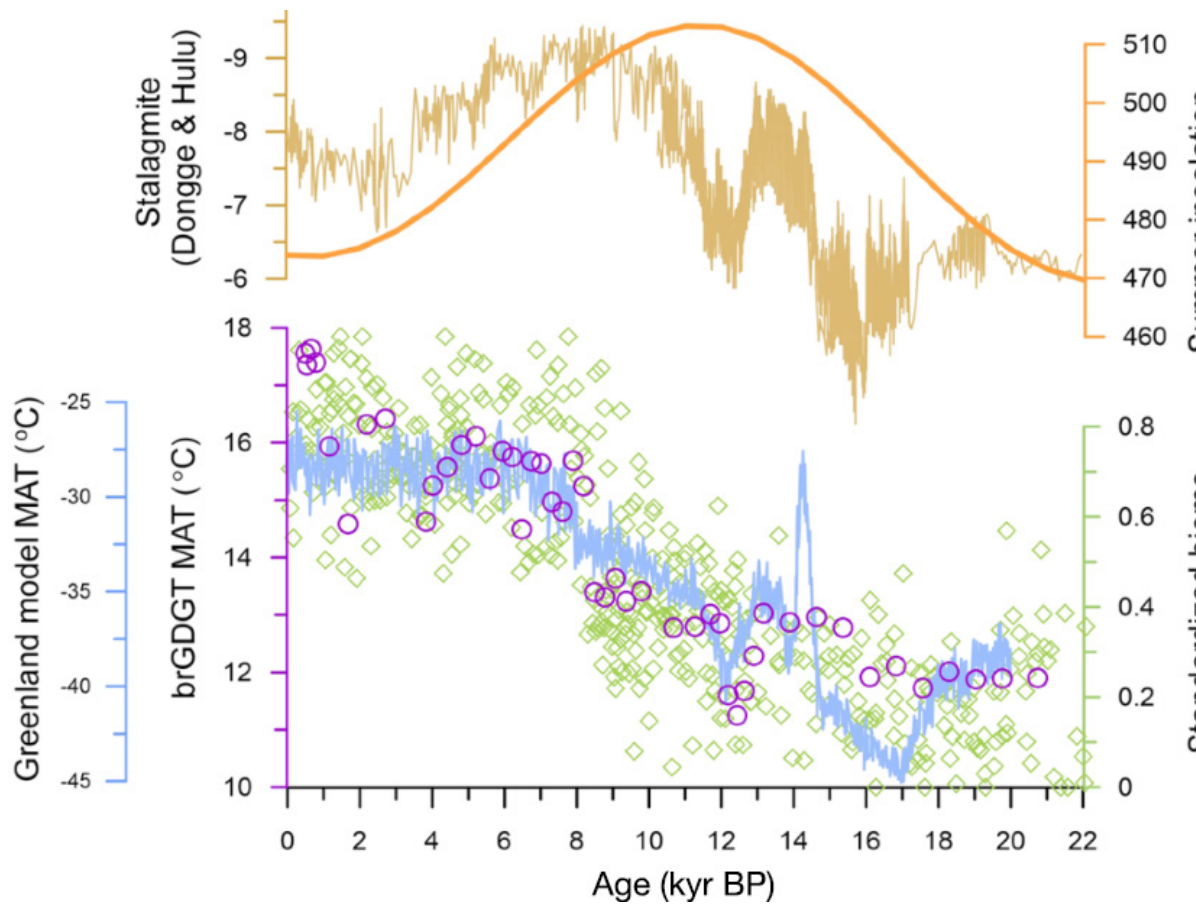

Figure 2: Standardized differences between EBL and DBL biome scores in the subtropical zone (pastel blue), reconstructed MAT based on biomarker result (brGDGT) from core SZY (circles), simulated annual mean temperature of Greenland (blue; Liu et al. 2014), and in top figure, oxygen isotopic curves from the stalagmite records of Dongge and Hulu caves (light brown) and summer insolation in $30^{\circ} \mathrm{N}$.

to EBL after the YD event is depicted in most records located north of the Tropic of Cancer. This post-YD large biome turnover originated in the northern tropical boundary of eastern Asia and progressively spread throughout all of subtropical China. The northernmost front of the EBL was reached around 8-7 kyr BP and corresponds to the northern limit of the East Asian Summer Monsoon. The progressive timing of the EBL expansion inferred from pollen records shows a significant delay with the speleothem oxygen isotope records from Dongge and Hulu caves from southern China.

The DBL/EBL biome turnover was quite synchronous over the same latitude, with a progressive time-lag from south (11.5 kyr BP) to north (8-6 kyr BP; Cheng et al. 2018; Zhou et al. 2016). Pollen data from the semi-arid belt in northern China under the influence of the summer monsoon also indicate a delayed expansion of the EBL biome during the early to mid-Holocene, which confirms the south-north progressive recolonization of the DBL biome over the ESA (Wang and Feng 2013).

The time-transgressive propagation of the EBL across the subtropical landscape stabilized during the mid-Holocene around 4 kyr BP. Pollen data relate an opening of the vegetation and the expansion of cultivated species towards the end of the Holocene that is probably related to a combined effect of a reduction of the annual amount of precipitation along with an increase in the regional anthropogenic disturbances. The modern range of the EBL biome in the subtropical zone seems to be constrained by the superimposition of the effects of increasing human activities (slash and burn, cultivation, etc.) and climate change.

\section{The causes}

The pattern of subtropical forest changes in response to the postglacial climate warming has drawn extensive attention (Lee and Liew 2010). The strengthening of the summer monsoon over the last post-glacial warming has been considered as the main factor driving large vegetation changes in eastern Asia (Zhou et al. 2016). Several speleothem records provide strong evidence for the strengthening of the monsoonal system (Dykoski et al. 2005); however, an increase in precipitation (annual and/or seasonal) may not be sufficient to explain a complete replacement of the DBL by an EBL biome at the scale of ESA.

The temperature reconstruction based on biomarkers and fossil pollen data reveals a threshold determined by the mean annual temperature for the EBL/DBL biome transformation during the early Holocene (Wang et al. 2017; Fig. 2). Today, the mean minimum temperature seems to be a more accurate or appropriate climate variable for defining the distribution boundary of EBL forest in China. The annual and winter temperature isotherms $\left(15-16^{\circ} \mathrm{C}\right.$ and $6-8^{\circ} \mathrm{C}$, respectively) delineates the northern limit of modern EBL forests in the subtropical mountains and corresponds to the transition between the DBL and EBL biomes. The temperature simulated by a transient model is consistent with the observed trend (Liu et al. 2009), and the combined data of biome transformation across the overall zone is coherent with the progressive increase in temperatures, which is controlled by winter insolation and seasonality during the last deglaciation to mid-Holocene. Thus, besides the strengthening of the monsoon, the turnover of EBL/DBL forest was probably extremely sensitive to both the seasonal amplitude and the long-term increase in winter and annual temperature during the early Holocene (Fig. 2).

The temperature increase and the seasonal change in precipitation are related to several global climate variables. The gradual increase in the sea surface temperature in the warm pool of the South China Sea and the northward crossequatorial atmospheric heat transport during the early to mid-Holocene have played an important role in heating up the subtropical continent. Besides the impact on the monsoonal system, the energy delivered to China increases de facto the inland temperature. The fact that the EBL forest recolonization was halted by the last Heinrich event and then the Younger Dryas, both of which are marked cool periods recorded in the North Atlantic, tends to suggest that global ocean circulation was also an important driving mechanism for the temperature changes over China, therefore impacting its large vegetation changes.

In conclusion, ESA underwent a large biome turnover that is clearly related to the post-glacial global climate changes, and the expected future climate changes will probably impact it again as was the case in the past.

\section{ACKNOWLEDGEMENTS}

This work was supported by the National Key R\&D Program of China (2016 YFA0600500) and the National Natural Science Foundation of China (No. 41230101).

\section{AFFILIATIONS}

'Guangdong Key Lab of Geodynamics and Geohazards, School of Earth Sciences and Engineering, Sun Yat-sen University, Guangzhou, China

${ }^{2}$ ISEM, University of Montpellier, CNRS, IRD, France

\section{CONTACT}

ZhuoZheng: eeszzhuo@mail.sysu.edu.cn

\section{REFERENCES}

Cheng Y et al. (2018) Earth-Sci Rev 182: 174-185

Dykoski CA et al. (2005) Earth Planet Sci Lett 233: 71-86

Fan D et al. (2016) Sci Rep 6: 31044

Lee C-Y, Liew P-M (2010) Palaeogeogr Palaeoclimatol Palaeoecol 287: 58-66

Liu Z et al. (2009) Science 325: 310-314

Liu Z et al. (2014) Quat Sci Rev 83: 115-128

Ni J et al. (2010) Palaeogeogr Palaeoclimatol Palaeoecol 289: 44-61

Nishimura M et al. (2014) Palaeogeogr Palaeoclimatol Palaeoecol 396: 75-92

Wang M et al. (2017) Chem Geol 463: 94-102

Wang W, Feng Z (2013) Earth-Sci Rev 122: 38-57

Wang X et al. (2018) Quat Sci Rev 192: 236-248

Yu SH et al. (2017) Quat Sci Rev 157: 114-128

Yue YF et al. (2012) Palaeogeogr Palaeoclimatol

Palaeoecol 365-366: 115-123

Zhao Y et al. (2009) Earth-Sci Rev 97: 242-256

Zhou X et al. (2016) Earth Planet Sci Lett 456: 39-46 